\title{
Cube Design Museum-Empathic Co-design for Societal Impact
}

\author{
Anja Köppchen
}

Cube design museum addresses current and future challenges within the broader context of an ageing and shrinking society, to improve the quality of life of people of all ages. This chapter presents the development of a tool, to stimulate and facilitate new, participatory ways of policymaking, to drive citizen engagement and bottom-up social innovation: the Co-Design Canvas. It has been co-designed and tested within the context of the village of Ransdaal in the Netherlands.

\section{Introduction}

Located in Kerkrade, a small town in the south-eastern corner of the Netherlands, next to the German border and about $15 \mathrm{~km}$ from Belgium, Cube design museum ${ }^{1}$ has been the first Dutch museum to be entirely dedicated to design. From 20152020, the museum was one of three institutions, including Columbus earth center and Continium discovery center, governed by the Museumplein Limburg Foundation, which is partly funded by the province of Limburg (regional government). Museumplein Limburg aims to empower citizens, by contributing to their social selfconfidence, economic self-reliance, and cultural awareness. It addresses questions

\footnotetext{
${ }^{1}$ Since 2021, Cube design museum is no longer operational, due to restructuring as a consequence of the Covid-19 crisis. Museumplein Limburg has combined its formerly three institutions into a new concept: Discovery Museum (www.discoverymuseum.nl).
}

The author is highly indebted to prof. Wina Smeenk (Inholland University of Applied Sciences), for her indispensable role in developing the Co-Design Canvas and thereby also in shaping the outcomes and learnings of Cube's co-design journey.

\footnotetext{
A. Köppchen ( $₫)$

Discovery Museum, Kerkrade, Netherlands

e-mail: a.koppchen@discoverymuseum.nl

(C) The Author(s) 2022

A. Deserti et al. (eds.), Co-creation for Responsible Research and Innovation, Springer Series in Design and Innovation 15, https://doi.org/10.1007/978-3-030-78733-2_11
} 
and challenges related to the earth, sustainability, science, technology, and design in the context of society, industry and education. More specifically, Cube focused on design for human needs and ambitions; i.e. design with societal impact.

The development of $\mathrm{Cube}$ coincided with a gradually growing awareness among the (international) museum community that museums need to constantly rethink their role and value for society, which requires more participatory approaches to actively engage the public $[1,7]$. Cube design museum did not only exhibit artifacts of design in the context of several social and environmental developments and challenges, but focused particularly on the process of design and its underlying needs and ambitions for societal change. A crucial part of the museum space was therefore dedicated to the design labs, where students and designers co-created with museum visitors and other stakeholders to tackle current and future societal challenges, based on design thinking and human-centred design. Evoking dialogue and debate with and among museum visitors was an important part of Cube's focus and practice.

The aim of SISCODE to experiment with a design-driven approach to co-creation in the fields of RRI and policymaking in different contexts throughout Europe provided an opportunity for Cube and Museumplein Limburg to both test and further enhance its capacity to engage multiple stakeholders in the process of design for societal impact. The project thus also served as a pilot to further explore the museum's role to empower citizens in the region to tackle current and future challenges.

In the context of the region's social challenges, Cube started this project with the aim to improve the quality of life of people living and growing up in an ageing society. Together with the nearby municipality of Voerendaal and citizens of one of its villages Ransdaal, the project gradually became more focused towards citizen participation and public engagement as being preconditions for a future proof society and quality of life for all citizens. In collaboration with municipal policymakers and highly engaged citizens, $C u b e$ re-framed the aim to design a tool that can stimulate and facilitate new, participatory ways of policymaking, in order to drive citizen engagement and bottomup initiatives. The project resulted in the development of the Co-Design Canvas: a tool for openly and transparently initiating, planning, conducting and assessing collaborations around societal challenges with multiple stakeholders. In short: an empathic co-design tool with societal impact.

\section{Ecosystem, Context and Challenge Addressed}

Cube's co-design journey needs to be understood in the context of the Netherlands' increasing political focus on citizen participation and the Limburg region's social challenges related to an ageing and shrinking population. The South Limburg region is a former coal mining area and constitutes the south-eastern periphery of the Netherlands. Since the shutdown of the mining industry in the 1960s and 1970s, Limburg has been going through several economic transitions, including the development of the chemical industry, smart services and leisure industries. Next to the region's 
economic development, Limburg is facing considerable demographic challenges due to a shrinking and ageing population.

Population ageing provides a variety of socio-economic policy challenges for EU, national, regional and local governments alike $[3,5,11]$. When the population is not only ageing but also shrinking, as is the case in South Limburg, the pressure on public services becomes even more apparent and social developments like increasing feelings (or fear) of loneliness add to the challenges' complexity.

In the last decades, the Netherlands is aiming to make a transition from a welfare state to a participation society, in which citizens are expected to take more responsibility for their own lives and surroundings [12]. Increasing focus on citizen involvement and public engagement in both national and local policy programmes is the result of a combination of austerity measures and a gradually changing perspective on how a healthy and sustainable society should function [2]. The role of the government and its relation to citizens is thus changing and new ways of interaction and collaboration are needed.

The small town of Voerendaal (approx. 12,500 inhabitants), which consists of five smaller villages, presents an exemplary case of the more widespread regional challenges as described above. The municipality's increasing need and desire to unfold more participatory ways of policymaking with the aim to improve its citizens' quality of life, in addition to their willingness to experiment and a highly engaged group of citizens in the village of Ransdaal (approx. 900 inhabitants), provided a good starting point for Cube's co-design journey.

In collaboration with Voerendaal policymakers from the social domain and a group of Ransdaal citizens including a citizens cooperative, $C u b e$ 's initial challenge became more and more focused and contextualised. From the start, policymakers and citizens shared the ambition to create and maintain a liveable and future-proof village. While a small group of Ransdaal citizens is highly engaged and employs many bottom-up initiatives, there is also the ambition to increase engagement and support among the entire community. There are always too many ideas and not enough people and resources. At the same time, the municipality is looking for ways to give its citizens more space to take matters into their own hands. In sum, policymakers and citizens felt the need to improve their collaboration and coordination of initiatives. The more concrete and re-framed aim of this co-design project became, therefore, to design a tool that can stimulate and facilitate new, participatory ways of policymaking, to drive citizen engagement and bottom-up initiatives.

\section{The Co-creation Journey}

Co-design processes are inherently iterative. For complex societal challenges, there is no one right solution available, which asks for an open-ended, non-linear approach. The four phases that have been defined in the SISCODE project of context analysis, problem reframing, envisioning solutions, and prototype development have served as guiding principles for planning and reflection in and on Cube's co-design journey. 
But the boundaries between these phases are blurred and most of the co-design practices focus on different phases simultaneously and involve a continuous back and forth between exploring, understanding, envisioning and creating. Therefore, instead of describing the process in a linear way as four subsequent phases, ${ }^{2}$ this section will highlight some key aspects and challenges that defined the evolution of Cube's co-design journey as an iterative learning experience.

\subsection{Framing and Reframing}

Starting from the broad context of quality of life in an ageing society, Cube's codesign journey involved a long phase of exploring different directions, contexts and (geographical) scopes. Different types of potential stakeholders were involved, including museum visitors, students, designers, researchers, and local and regional policymakers. This led to a large collection of needs, ambitions, questions and ideas, varying from highly personal or technical ideas, such as a robot play buddy for lonely children among an ageing population, to more conceptual ideas for a participatory community such as a future citizen lab. Especially the first half of the journey has been a process of constantly diverging and converging, of zooming in and zooming out.

To facilitate this process with different groups of stakeholders, Cube regularly used the tool of Frameboards [9]. This canvas has become part of a well-established method at the Cube design labs to turn the process of framing into a conscious practice. The Frameboard Canvas is used to capture and visualise both the challenge and possible solution spaces and ideas for specific target groups, which then serves as a boundary object [10] to reflect on the ideas with other stakeholders. In this way, frameboards facilitate the iterative and exploratory nature of the process in which ideation and re-framing is part of the same process that Stompff calls 'learning by creating' [9]. Every workshop, conversation, prototype, or test generated new ideas that brought the team closer to a solution, while it also increased the team's understanding of the challenge and its underlying factors. One of the most significant reframing processes in Cube's journey took place in close collaboration with the municipality of Voerendaal and the citizens of Ransdaal, which led to a shift from ageing to the question of citizen participation as a way to support quality of life in a more future oriented context. However, even with this more concrete context defined, it took many rounds of reframing, envisioning, and reflection, before the first version of the final prototype took shape.

\footnotetext{
${ }^{2}$ For a more comprehensive description of Cube's activities and challenges in the four co-design phases, see chapter 4.8 of the SISCODE deliverable 3.4 [6].
} 


\subsection{Tools and Sites for Co-Creation}

In a co-design process, various stakeholders collaborate and co-create to tackle societal challenges through participatory and creative methods. The SISCODE toolbox provides a comprehensive collection of existing (design) tools to support this process. In addition to the frameboards as discussed above, $C u b e$ has experimented with many tools and methods both from the SISCODE toolbox and beyond [13], with varying results. Cube learned that the efficacy of such tools largely depends on the situation and the preference and knowledge of participants and facilitators. Whichever tools were used, their main role has been to provide a shared language and understanding among the participants, to make sense of data, and to evoke new perspectives and collective creativity. Working with different tools in several workshops led to many tangible outcomes including mood boards, mind maps, customer journeys and rapid prototypes. Making ideas tangible and visual has been extremely important to keep stakeholders engaged, helping them to better grasp the potential value of an intended solution.

Along with the tools, the settings in which Cube organised co-design and cocreation activities affected the process and outcomes, which points to the role of space and place in human interactions. For Cube's journey, three types of sites for cocreation were selected or established: the creative lab spaces of $C u b e$ design museum, locations within the context of the challenge (i.e. Voerendaal and Ransdaal), and virtual spaces through online activities. Each site comes with specific opportunities and limitations.

The Cube design labs provided a creative, inspirational and flexible space that enables people to get out of their daily routines and thus see things in a different light. In addition to inviting stakeholders to the lab for a workshop or co-design session, Cube also used the space to organise informal and spontaneous sessions with museum visitors who were not directly involved in the challenge. This provided the team with new insights and reflections from a broader perspective. While the lab can inspire and encourage people to get out of their comfort zones and bring in new perspectives, it can also be a threshold for some to participate, precisely because it is distant from the real context. Cube organised several sessions in the local community centre of Ransdaal, which provided a familiar and safe space for especially those citizens who might not feel comfortable to enter into a design process, and where the barrier to participate is literally smaller. To encourage the creative process, tools and methods were brought into the village, which created very similar opportunities as the labs in Kerkrade. The third type of location has been created out of necessity, as a consequence of the meeting limitations due to the COVID-19 pandemic since March 2020. There are obvious advantages, because there is no need for physical spaces and travelling, and it has made recording and storing of outcomes much easier. However, Cube also encountered significant challenges, especially in terms of limited human interaction and inclusivity. Still, even though online conversations cannot replace real-life interactions, experimenting extensively with different online 
tools increased Cube's knowledge and expertise, and provided a valuable addition to its already familiar collaboration tools and ways of working.

\subsection{Stakeholder Engagement: Learning About Power, Trust and Empathy}

As has already been stressed, co-design is about engaging multiple stakeholders in a collaborative endeavour to achieve positive change. The most important stakeholders in Cube's journey to achieve new, participatory ways of policymaking and to drive citizen engagement and bottom-up initiatives, were municipal policymakers and citizens. The groups of stakeholders participating in the co-design sessions organised by $C u b e$ varied in size and composition. Many participants were not involved throughout the whole process. Eventually, only a small number of highly dedicated stakeholders were closely involved in developing and testing the final prototype. This group consisted of three policymakers from the department of social development at the municipality of Voerendaal (one alderman and two civil servants) and five highly motivated citizens of the village of Ransdaal, including members of the citizens cooperative 'Ransdaal voor Elkaar'.

This evolution of participating stakeholders presents an important learning outcome. Although the workshops were considered successful in terms of providing new insights based on open and constructive dialogue, they also caused frustration and scepticism among some citizens and policymakers. It turned out challenging for people to get into the flow of design thinking, embracing an open-ended process, and not to expect immediate and concrete results. Cube thus learned about the need to manage expectations, to prevent drop-outs throughout the process.

Another challenge in terms of stakeholder engagement relates to questions of power and trust. Unequal power relations were sensed frequently during workshops. But it was only in the later phases of the journey when the prototype of the CoDesign Canvas was being tested, that these power relations were openly and explicitly addressed. This resulted in an increased awareness among stakeholders about their different roles and perceptions, and about how stakeholders' different languages can lead to misconceptions and a lack of trust and understanding.

Cube involved empathic co-design expert Wina Smeenk [8] in the last phase of the journey to address these challenges, to support the team by organising and facilitating co-design sessions, and by designing a testable prototype. Citizens and policymakers were in need for more guidance in co-designing new ways of working and collaborating. In particular the group of Ransdaal citizens indicated the need of a clear co-design process for their citizen initiatives and the need to make the process more tangible for testing. Initiated by Wina Smeenk and inspired by the Design Choices Framework of Lee et al. [4], the Co-Design Canvas was being developed through several rounds of (online) testing between March and November 2020. 


\section{Experimentation: Output, Transformations, Outcomes}

The Co-Design Canvas is a tool that supports the facilitation of an open, transparent dialogue about all stakeholders' experiences and interests, the alignment of expectations and goals, the creation of insights and understanding, and the exchange of knowledge, power relations and shared responsibilities in planning, conducting and assessing a co-design process. Throughout its journey, Cube learned that problems in collaborative processes often arise from tensions between the people and organisations involved, for instance due to power imbalance or (social) contingencies that evolve, were not foreseen nor discussed beforehand. The canvas can clarify these issues and relationships, and offer those involved stakeholders a common language and method to reflect on and in the process. Co-design processes require dialogue, transparency, and empathy. The Co-Design Canvas can help facilitate these processes and create insight into why processes succeed or fail (Fig. 1).

The design of the canvas is aiming at a comprehensive, yet flexible and easy to use tool, that can be adopted to different contexts, needs, and phases of the process. It identifies eight interdependent variables that influence the process: the context, the purpose of change, the stakeholders, the results, the impact, and the co-design focus, setting, and activities. The canvas integrates these variables into process cards, which can be discussed separately, without a fixed order. After all, a co-design project is an iterative and joint learning process. When put together, the cards create one canvas to see the bigger picture and address the relations between the variables. The front of the cards contain guiding questions to stimulate the discussion, providing room to write, draw, or put sticky notes. On the back there is more information about each card's purpose, as well as some tips \& tricks and additional tools to get stakeholders started. These include tools from the SISCODE toolbox and other design thinking and social innovation methods. Building on the iterative and open-ended nature of a co-design process, the canvas is a dynamic tool that can and should be used multiple times

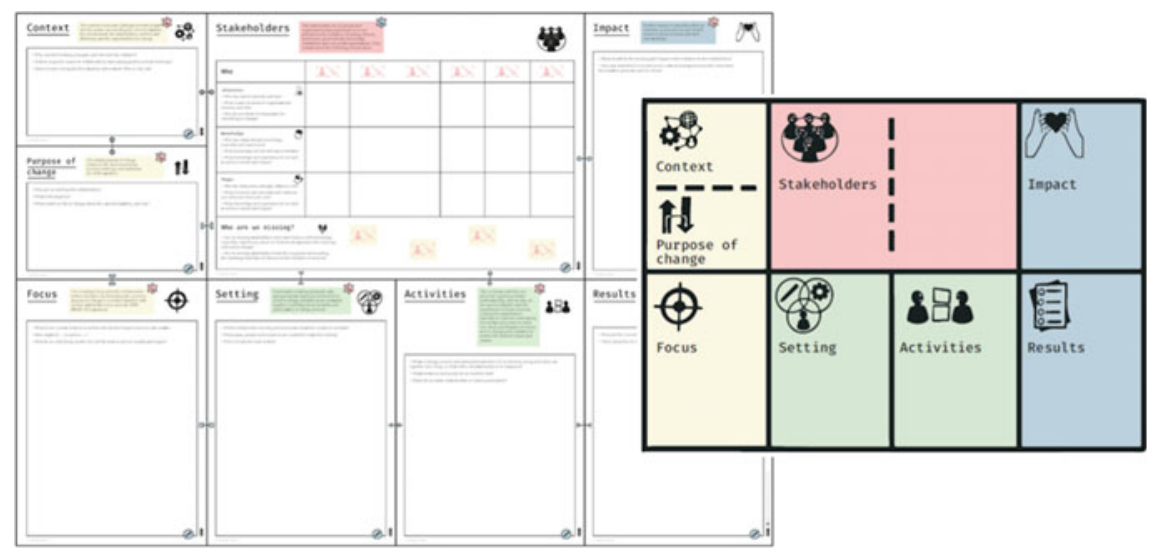

Fig. 1 The co-design canvas (left) and a schematic representation of the canvas cards (right) 
during different phases and whose content is constantly changing. The Co-Design Canvas is a tool for initiating, planning, conducting and assessing collaborations around societal challenges with multiple stakeholders openly and transparently.

\section{Lessons Learnt and Reflections}

One of the underlying assumptions of the SISCODE project and of Cube's pilot, is that co-design approaches can support an effective interaction between policymakers, citizens and other stakeholders. Drawing on the museum's experience with design thinking and co-creation, this project provided a valuable opportunity for Cube to further explore and develop its potential role in these kinds of multi-stakeholder collaborations. Several enthusiastic reactions from different stakeholders and policy and research institutions who have tried and tested different versions of the canvas, have encouraged the organisation to continue developing its participatory approach with artists, designers, researchers, policymakers, and last but not least citizens.

The Co-Design Canvas was produced in physical form under Creative Commons licence in February 2021. In addition to the eight cards, it consists of a booklet that contains practical guidance and illustrated instructions to support the actual use of the canvas by different stakeholders. However, even though considerable time and effort has gone into testing and revising this prototype to make it as practical and intuitive as possible, the tool itself doesn't make an impact. It can only support social change, which ultimately requires changing mindsets and practice.

Both policymakers and citizens have expressed their motivations to use the CoDesign Canvas in future citizen initiatives and participation strategies. But there has been no clear agreement on how to further develop and implement it in a collaborative manner. It seems that equal collaboration between citizens and policymakers is not yet an established routine, which confirms one of Cube's experiences that changing relations and expectations, as well as creating trust and understanding takes time and a certain openness to change and reframe.

In order to structurally implement more participatory ways of policymaking furthermore requires different ways of working across the municipality, including other departments like spatial planning. This involves some political decision making as well. Moreover, the municipality's civil servants have indicated that they might need more support or training on how to facilitate working with the canvas. They have set up a preliminary implementation plan, which includes a workshop facilitated by Cube, to introduce the tool and methodology to a more diverse group of policymakers within the municipality. They will then work with the canvas in different projects for a specified period of time, after which the method and experiences will be evaluated.

Sustainable implementation thus takes more time and practice. And with time and practice, the Co-Design Canvas might (or should?) change as well, which is part of an iterative learning process. After all, a tool is just a tool. The best tools, methods or procedures are of no use if they don't fit the mindset and attitude of the participating stakeholders or if there is a lack of respect, equality, and empathy. 


\section{References}

1. Bunnik C (2014) Musea voor Mensen. Museumvereniging, Amsterdam, Amsterdam

2. De Haan E, Meier S, Haartsen T, Strijker D (2018) Defining 'success' of local citizens initiatives in maintaining public services in rural areas: a professional's perspective. Sociologia Ruralis 58:312-330

3. Kotzeva M et al (2015) People in the EU: who are we and how do we live? Publications Office of the European Union, Luxembourg

4. Lee J-J et al (2018) Design choices framework for co-creation projects. Int J Des 12(2):15-31

5. Meuwissen J, Severijns B, Gardeniers J (2017) Begeleidende notitie bij de resultaten van Progneff. Etil Research Group, Maastricht

6. Real M et al (2020) SISCODE deliverable 3.4: experimentation report—Lab's journeys as case-studies

7. Simon N (2010) The participatory Museum. Museum 2.0

8. Smeenk W (2019) Navigating empathy: empathic formation in co-design. Doctoral Dissertation, Eindhoven University of Technology

9. Stompff G (2018) Design thinking: radicaal veranderen in kleine stappen. Boom uitgevers, Amsterdam, Amsterdam

10. Stompff G (2020) De Kracht van Verbeelden: design thinking in teams [inaugural speech, 27 Nov 2020]. Inholland University of Applied Sciences

11. Te Riele $S$ et al (2019) PBL/CBS Regionale bevolkings-en huishoudensprognose 2019-2050. Statistics Netherlands, The Hague

12. Van Houwelingen P, Boele A, Dekker P (2014) Burgermacht op eigen kracht? Een brede verkenning van ontwikkelingen in burgerparticipatie. Netherlands Institute for Social Research (SCP), The Hague

13. Willenborg A, Smeenk W (2017) Shake it! Een design thinking-spel voor innovatie en transformatie. Boom Uitgevers, Amsterdam

Open Access This chapter is licensed under the terms of the Creative Commons Attribution 4.0 International License (http://creativecommons.org/licenses/by/4.0/), which permits use, sharing, adaptation, distribution and reproduction in any medium or format, as long as you give appropriate credit to the original author(s) and the source, provide a link to the Creative Commons license and indicate if changes were made.

The images or other third party material in this chapter are included in the chapter's Creative Commons license, unless indicated otherwise in a credit line to the material. If material is not included in the chapter's Creative Commons license and your intended use is not permitted by statutory regulation or exceeds the permitted use, you will need to obtain permission directly from the copyright holder.

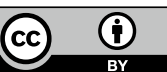

